\title{
La obligación de aplicar las normas jurídicas vigentes
}

\author{
LORENZO PEÑA ${ }^{1}$ \\ Instituto de Filosofía del CSIC \\ Grupo de Estudios Lógico-Jurídicos (JuriLog)
}

\begin{abstract}
RESUMEN. Es tarea de todos aplicar una ley, o sea realizar y ejecutar aquellos actos jurídicos y hechos prácticos que desembocan en su cumplimiento o lo constituyen. Se aplica una norma de carácter implicativo cuando, ante la existencia de un supuesto de hecho previsto en ella, se concluye la obligación (o licitud) contenida en su consecuencia jurídica, actuándose de conformidad con ello. Eso es incompatible con la separación de lo normativo y lo fáctico, propia del normativismo de Kelsen. Y es que hay situaciones jurídicas que es imposible que se den cuando suceden ciertos hechos. El cambio de paradigma requerido para entender el hecho jurídico pasa por adoptar una lógica jurídica totalmente diferente de la lógica deóntica estándar.
\end{abstract}

Palabras clave: aplicación de la ley, normativismo, lógica jurídica, razonamiento práctico, lógica deóntica, hecho jurídico.

\section{Introducción}

Aplicar una norma vigente es traducirla a la praxis. Cuando hablamos de normas inaplicadas o inaplicables queremos decir que no determinan la situación real, la cual está en contradicción con la norma. Mas ese tránsito de la norma en sí a la praxis comporta dos pasos, cada uno de los cuales es una aplicación de la norma en cierto sentido: $\left(1^{\mathrm{o}}\right)$ volcar la norma general o
ABSTRACT. To apply a law is a task incumbent on everybody, since it consists in accomplishing such juridical acts as ensue from the norm when certain factual situations are encountered and in fulfilling the apposite material facts. A norm-application is nothing else but drawing practical consequences from the norm plus the existence of such facts as constitute the norm's antecedent. That operation in incompatible with Kelsen's normativism, which pronounces norms to be completely separated from facts. Thus, certain legal situations are inconsistent with certain facts. In order for us to understand the rationale of norm applications we need a legal logic entirely different from standard deontic logics.

Key words: norm application, normativism, legal logic, practical reasoning, deontic logic, juridical fact

abstracta en situaciones jurídicas singulares o concretas; y $\left(2^{\circ}\right)$ llevar la realidad a conformarse con esas situaciones jurídicas concretas.

¿Qué principios o reglas hacen viable esa doble aplicación? ¿Son principios lógicos, son principios extra-lógicos? ¿Cuál es su fundamento? ¿Qué garantiza que todos los entiendan y los usen correctamente? ¿Qué pasa si no se usan, o sea si la norma no viene aplicada? Y 
¿por qué vía casi milagrosa se produce esa hibridación de lo normativo y lo fáctico? ¿Hay acaso condiciones normativas para la verdad fáctica y condiciones fácticas para la vigencia normativa?

Tales son las cuestiones abordadas en este artículo.

\section{Acercamiento lexicográfico}

Sin pretensión de sustituir el análisis conceptual por una exploración lexicográfica, ésta no está de más para acercarnos a dilucidar la noción de aplicación normativa.

Al hablar de la aplicación de las normas, usamos el verbo "aplicar" en un sentido igual $-\mathrm{O}$ al menos similar- al que tiene en general referido a cualesquiera reglas. Aplicar reglas de alguna índole es llevar a cabo una praxis en la cual esas reglas se ejecutan, un hacer ajustado a las reglas.

Por lo menos así es cuando las reglas se aplican bien. Cuando se aplican mal, la praxis se aparta o desvía de las reglas, aunque quien la efectúe haya invocado tales reglas. Mal aplicar una regla es un modo de no-aplicarla. Eso vale lo mismo para reglas de cocina o de etiqueta o del arte bélico que para reglas de canto, de tinte, de redacción o de oratoria forense.

Más ampliamente todavía, podemos hablar de aplicación con relación a cualquier saber susceptible de tener un interés técnico, o sea de guiar a una praxis que, en la medida en que se deja efectivamente guiar por ese saber, es una aplicación del mismo.

Hay otro sentido afín pero distinto: aquel en que un saber, que no es todavía una praxis mas sí sirve de guía o de regla a la praxis, se ajusta o acopla a un saber más puramente teórico. Ese saber directamente utilizable como guía práctica es una aplicación del saber teórico. La ciencia aplicada es la técnica; la filosofía aplicada es la moral especial ${ }^{2}$.
Vemos así dos acepciones emparentadas, próximas, mas no coincidentes. En un sentido, aplicar es pasar de la teoría a la praxis. En el otro es pasar de una teoría teorética a una teoría práctica, o más cercana a la práctica.

Si nos remontamos a la etimología del verbo latino "adplicare" (transformado -por asimilación fonética- en "applicare"), vemos que es un derivado de "plicare" ("plegar", "enlazar", "conectar") mediante el prefijo (preposición) "ad", que denota tendencia-hacia. "Applicare" es acercar una cosa a otra hasta ponerlas en contacto estrecho o inmediato; y, de ahí, vienen otras acepciones: unir una cosa a otra, y, como verbo reflexivo, consagrarse a una tarea o actividad.

\section{El principio de aplicación deóntica}

Esa digresión lexicográfica nos sugiere que la aplicación normativa es un acercamiento de la norma -que es una reglaa la praxis ajustada a tal regla; ya sea directamente la ejecución de la regla, ya sea la elaboración de una regla intermedia por la cual se pase de la regla así aplicada a la praxis de ejecución.

Esas consideraciones nos inspiran una cuatripartición de las aplicaciones normativas. Las normas (jurídicas o no jurídicas) suelen ser de contenido implicativo o condicional: siendo imperativas, suelen ser de contenido implicativo $-\mathrm{O}$ sea "Es obligatorio que, en la medida en que $\mathrm{A}, \mathrm{B}$ "- $\mathrm{o}$ de contenido condicional -o sea, "Es obligatorio que, si A, B"-; siendo permisivas, suelen ser de una de esas dos formas, sustituyendo "obligatorio" por "lícito". De momento voy a fijarme sólo en normas imperativas implicativas (tratando de dejar de lado -hasta donde quepa y sólo para los fines de este artículo- la diferencia entre la implicación, "en la medida [al menos] en que", y el mero condicional, "si...entonces"). 
Represento formalmente " $\mathrm{A} \rightarrow \mathrm{B}$ " como una implicación que significa que, (por lo menos) en la medida en que A, B.

Sentado lo cual, podemos ver una norma imperativa de contenido implicativo como expresable mediante una fórmula del tipo " $\boldsymbol{o}(\mathrm{A} \rightarrow \mathrm{B})$ ", donde " $\boldsymbol{o}$ " es el operador deóntico de obligatoriedad. Aunque creo que los problemas lógicofilosóficos esenciales son los mismos para la obligatoriedad del orden jurídico o de cualquier otro, me limito a considerar aquí la jurídica.

Para un correcto tratamiento lógico de las normas imperativas de contenido implicativo, vamos a tener en cuenta el principio de aplicación, que es una regla válida en nuestro sistema LJ de lógica juridicial: "o $(\mathrm{A} \rightarrow \mathrm{B}) \supset(\mathrm{A} \rightarrow \boldsymbol{o} \mathrm{B})$ "; o sea, si es obligatorio que, en tanto en cuanto $\mathrm{A}, \mathrm{B}$, entonces, en la medida (al menos) en que suceda que $A$, será obligatorio que $\mathrm{B}^{3}$. Conviene señalar que ese principio de aplicación está, en nuestra lógica juridicial, sometido a restricciones: "A" $\mathrm{y}$ " $\mathrm{B}$ " han de designar estados de cosas contingentes de suyo y contingentes entre $\mathrm{si}^{4}$.

Veamos, entonces, las ya anunciadas cuatro acepciones emparentadas.

$1^{\text {a }}$. Dada la norma “ $\boldsymbol{o}(\mathrm{A} \rightarrow \mathrm{B})$ ", y dado el hecho de que A, aplicar esa norma es establecer la obligatoriedad de B mediante un acto jurídico.

$2^{a}$. En tal supuesto, aplicar la norma es mandar ejecutar, o ejecutar efectivamente, la realización de la apódosis, o sea de B.

$3^{\mathrm{a}}$. En el mismo supuesto de hecho, A, aplicar la norma “ $\boldsymbol{o}(\mathrm{A} \rightarrow \mathrm{B})$ " es extraer la deducción lógico-jurídica: la obligatoriedad de B.

$4^{a}$. En el mismo supuesto, aplicar esa norma es ajustar la propia conducta a la prescripción de "oB" y, por lo tanto, realizar B.

\section{Dilucidación de las cuatro acepciones}

La diferencia entre la acepción $1^{\mathrm{a}}$ y la $3^{\mathrm{a}}$ estriba en que en la $1^{a}$ es menester un acto jurídico, en el cual -constatada o reconocida la factualidad del supuesto, A- se declara la obligación de su consecuencia jurídica, B. En cambio, en la acepción $3^{\mathrm{a}}$ se prescinde de tal acto jurídico: el mero reconocimiento del supuesto de hecho, más la deducción lógica, lleva al reconocimiento de la consecuencia jurídica.

Una conexión entre las acepciones $1^{\mathrm{a}}$, $2^{\mathrm{a}}, 3^{\mathrm{a}}$ y $4^{\mathrm{a}}$ estriba en que, igual que quien realice el acto jurídico declaratorio de la obligación de $\mathrm{B}$, en la acepción $1^{\mathrm{a}}$, sólo verá su tarea realizada con éxito si se ejecuta $\mathrm{B}$ (y, cuando quien dicta el acto es un tribunal, su misión sólo culmina con la ejecución voluntaria o forzosa de esa obligación o de otra supletoria), del mismo modo el mero reconocimiento de la obligación de B queda frustrado si quien lo reconoce no cumple esa obligación, cuando está en su mano.

Como vemos, el enlace entre las acepciones $1^{\mathrm{a}}$ y $2^{\mathrm{a}}$ es el mismo que entre la $3^{\mathrm{a}}$ y la $4^{\mathrm{a}}$. Es obvio el vínculo entre la $1^{\mathrm{a}}$ y la $3^{\mathrm{a}}$. Las acepciones $3^{\mathrm{a}}$ y $4^{\mathrm{a}}$ son actos o hechos de cumplimiento de la norma, que son también aplicaciones de ésta.

¿En qué casos procede efectuar una aplicación en la acepción $1^{\mathrm{a}}$ y en cuáles procede hacerlo en la acepción $3^{\mathrm{a}}$ ? La aplicación en la acepción $1^{\mathrm{a}}$ es un acto jurídico en el cual la persona o institución encargada de efectuarlo está legalmente habilitada para hacer la constatación de la prótasis, A, y por ende para declarar la obligación de B. Esa persona individual o colectiva puede ser pública o privada. No tiene forzosamente que ser un órgano jurisdiccional. Puede ser un funcionario o agente público, en la esfera de su competencia: un registrador de 
la propiedad, un notario, un jefe de servicio. Formalmente acreditados unos hechos según la regulación legal, el registrador emite un acto jurídico que, explícita o implícitamente, determina obligaciones para terceros.

En la acepción $3^{\mathrm{a}}$ se hace la economía de ambas cosas, de esa constatación de A y de ese pronunciamiento de la obligación de $\mathrm{B}$, para poder meramente concluir o reconocer -por pura lógica- tal obligación simplemente a partir de la factualidad de A.

La aplicación de la acepción $1^{\mathrm{a}}$ es una aplicación que crea o declara una obligación, la de $\mathrm{B}$, que, sin ese acto, no existiría o cuya existencia sería dudosa a pesar de la existencia del supuesto de hecho, A. Se requiere aplicar una norma en esa acepción $1^{\mathrm{a}}$ siempre que la norma vincule obligatoriamente una consecuencia jurídica, B, a un supuesto de hecho, A, que sea de problemática constatación o calificación, por la razón que fuere, y cuya admisión -a efectos de surtir consecuencias jurídicas- requiera, por mandamiento legal, el pronunciamiento explícito de cierta persona o institución.

En cambio, en los casos en que eso no hace falta, estamos en la acepción $3^{\mathrm{a}}$.

Ahora bien, cuando hace falta acudir a una aplicación de la acepción $1^{\mathrm{a}}$-porque el reconocimiento del supuesto de hecho, A, es asunto polémico-, tenemos todavía dos casos que hay que diferenciar: aquel en que quien emite el acto jurídico se limita a declarar la obligación (preexistente) de B y aquel en que crea esa obligación. En un acto declarativo, el emisor del mismo reconoce una obligación que ya se estaba dando antes de la declaración -que se estaba dando en virtud de la lógica jurídica

Notemos que entre esos supuestos de hecho, A, algunos de ellos pueden consistir en que el encargado de emitir el acto jurídico tenga por conveniente esa consecuencia jurídica, B, para alcanzar ciertos fines legítimos. Es un tipo de supuesto de hecho peculiar, que el aplicador descubre por introspección: se da cuenta de que está persuadido de que existe tal nexo. Con otras palabras, estamos ante una norma de rango superior que confía a una autoridad o a un particular dictar o efectuar un acto jurídico que cree una situación jurídica, en la medida en que esa autoridad o ese particular piensen que es necesario para alcanzar un fin legítimo (no un fin cualquiera, sino uno de una lista tasada que marca la ley y que somete a limitaciones).

Ejemplos de lo cual podemos poner muchos: la Constitución impone al legislativo establecer obligaciones en la medida en que lo estime necesario para la realización de los valores, principios y derechos fundamentales reconocidos en la norma suprema; la ley impone al ejecutivo el deber de establecer las obligaciones que estime oportunas para dar cumplimiento a los fines cuya vigencia se establece en esa misma ley (reglamentos de desarrollo de la ley -p.ej. para regular la adquisición de la nacionalidad española); la Carta de la ONU impone al consejo de seguridad el deber de, en la medida en que lo juzgue necesario para salvaguardar la paz, crear situaciones jurídicas internacionales vinculantes; las leyes imponen al juez, en una serie de casos, el deber de crear nuevas situaciones jurídicas (incluyendo obligaciones) cuando estime que son necesarias para alcanzar ciertos fines legítimos (p.ej. un reparto justo de la herencia cuando uno de los herederos ha pedido la partición; o la adjudicación de un bien concreto del deudor al acreedor cuando el propio deudor ha dejado pasar el plazo para seleccionarlo él mismo).

En todos esos casos tenemos un acto jurídico discrecional, mas no por ello 
arbitrario, ya que la norma de rango superior obliga al encargado de emitir el acto jurídico a hacerlo porque cree que el contenido de tal acto es necesario para alcanzar ciertos fines legítimos -insisto en que no se trata de un fin cualquiera que sea legítimo, sino de un fin determinado que marque la ley-. La autoridad o la persona o institución que, en cumplimiento de esa norma superior, emita tal acto jurídico sólo estará con ello aplicando la norma cuando el acto reúna tres requisitos:

$1^{\circ}$ ) La declaración de necesidad es veraz (si no, hay prevaricación).

$2^{\circ}$ ) Está fundada en un razonamiento $-y$, en la medida de lo posible, obtenida en un proceso contradictorio y con asesoramiento de expertos y consulta a los afectados y a la opinión pública.

$3^{a}$ ) Hay proporción y no desmesura (toda competencia reglada es tasada y sujeta a un principio general del derecho, el de proporcionalidad).

La discrecionalidad legal es, pues, reglada y no excluye la obligación de motivar las decisiones (salvo en aquellos casos en los que la norma exima al titular del acto de esa obligación de motivación, p.ej. cuando se trata de designar cargos de confianza, pues -como gráficamente lo expresó un político españolen tales casos basta, para una destitución, que el así destituido ya no goce de la confianza del designador).

En la mente de todos están actos jurídicos (p.ej. algunos recientes y menos recientes de organismos internacionales) en los que, afirmándose falazmente que se estaba aplicando la norma implicativa, no era así, porque patentemente no había proporción, porque no se había alcanzado la proclamación de la necesidad por una vía de debate contradictorio, o porque incluso hay vehementes sospechas de prevaricación (insinceridad y mentira del emisor del acto).

Como ya lo hemos dicho, el encargado de la aplicación, en la acepción $1^{\mathrm{a}}$, puede también ser un particular. Así, las leyes y reglamentos pueden imponer a los titulares o gerentes de establecimientos abiertos al público el deber de, en la medida en que un cliente actúe de manera peligrosa para los demás (o para la seguridad pública), expulsarlo. En tal caso, al emitir la orden de expulsión, el titular del establecimiento está efectuando un genuino acto jurídico que hace nacer para el expulsado la obligación de abandonar el local; la constatación del comportamiento peligroso es discrecional (pero no arbitraria o inmotivada, sino susceptible de impugnación jurisdiccional).

En vez del rodeo de la acepción $1^{\mathrm{a}}$, estamos en la acepción $3^{\mathrm{a}}$ de la aplicación cuando la propia ley lo autoriza y cuando no prevé ningún cauce procesal, sino que deja la aplicación (ahora en la acepción $3^{\mathrm{a}}$ ) a los sujetos de derecho. Un ejemplo de automatismo legal se da en la compensación de deudas. Aquí la aplicación se hace ope iuris. Si te debo 300 y tú me debes 250 , la regla jurídica de compensación de deudas determina automáticamente que nuestras relaciones de débito se reducen a que sólo te debo 50; no hace falta que ningún juez lo decida. Mas, como esa regla tiene sus limitaciones -p.ej. en derecho mercantil y en derecho tributario-, ante una deuda mutua en particular, podría requerirse todavía una operación intelectual de subsunción para saber que la situación entra en el ámbito de la regla de compensación 5 .

Podemos hallar muchísimos otros ejemplos de aplicación de las normas en las acepciones $3^{\mathrm{a}}$ y $4^{\mathrm{a}}$. La norma tributaria nos impone la obligación de: hacer declaración de la renta en la medida en que sea verdad que ganamos al año más 
de tanto; ganamos al año más de tanto (supuesto de hecho); luego (eso lo sabe cualquiera) tenemos obligación de hacer la declaración. (Hay una complicación con un cuantificador universal implícito, que de momento paso en silencio para simplificar.) Si sólo lo reconocemos, hemos hecho una aplicación en la acepción $3^{\text {a }}$. Si lo cumplimos, en la $4^{\text {a }}$.

Para cerrar este apartado conviene decir que, cuando se habla de problemas de inaplicabilidad de una norma, puede estarse aludiendo a diversos tipos de dificultades. Si se toma en la acepción $1^{\mathrm{a}}$, dificultades para dictar o declarar esa obligatoriedad, por ser los hechos oscuros, embrollados, o de ardua y escabrosa constatación, subsunción o calificación, o por lo duro o injusto que resulte decidir o proclamar esa consecuencia jurídica. Si se toma en la acepción $2^{\mathrm{a}}$, por obstáculos prácticos que se interpongan para la ejecución (p.ej. falta de medios, resistencias o incluso simultánea vigencia de otras normas que prohíban la ejecución, produciéndose un conflicto normativo). Si se toma en la acepción $3^{a}$, la dificultad puede estribar en la escasa capacidad razonadora, o en problemas psíquicos de un cierto grupo de obligados. Y, si se toma en la acepción $4^{\mathrm{a}}$, dificultades prácticas del tipo que sean, o morales, o incluso conflictos normativos.

El legislador no puede desconocer tales dificultades. Fracasa si produce una obra legislativa que, por chocar con muchas dificultades, vaya a quedar inaplicada en buena medida (en cualquiera de las cuatro acepciones). A la postre, como veremos, la ley sistemáticamente inaplicada no es ley.

\section{El principio de retro-aplicación}

Aplicar es acercar. Aplicar la norma implicativa es ir de arriba abajo: es pasar de esa norma -aún alejada de la praxis- a una norma más próxima a tal praxis, o directamente a la praxis misma (al cumplimiento o ejecución). ¿En qué es más distante de la praxis la norma " $\boldsymbol{o}(\mathrm{A} \rightarrow \mathrm{B})$ " que "oB"? En que, quien se dispone a cumplir la $1^{\mathrm{a}}$, tiene que conseguir que $\mathrm{A} \rightarrow \mathrm{B}$,lo cual no es todavía una tarea concreta de hacer que B. P.ej., si A es que uno gane más de mil euros mensuales y $\mathrm{B}$ es hacer declaración de renta, se puede cumplir $\mathrm{A} \rightarrow \mathrm{B}$ renunciando alexcedente de ingresos de rebase 999 euros. La norma $\boldsymbol{o B}$ impone inmediatamente la tarea de hacer B. Ante la duda de qué hacer, la obligación implicativa $\boldsymbol{o}(\mathrm{A} \rightarrow \mathrm{B})$ deja incógnitas u opciones (al menos en algunos casos), mientras que la obligación $\boldsymbol{o B}$ orienta decididamente la acción (al menos en ausencia de obligaciones contradictorias con ésa).

Mas, si el camino de la teoría normativa a la praxis pasa por esa aplicación (sea en la acepción $1^{\mathrm{a}}$ o en la $3^{\mathrm{a}}$ ), el camino inverso de la praxis a la teoría buscará hipotéticos fundamentos que justifiquen ese paso, aspirando así a ir de abajo arriba. Esa indagación parece razonable si queremos averiguar el porqué de la aplicabilidad de las normas. ¿Qué nos permite usar ese principio de aplicación?

Sin embargo, es muy problemático que haya fundamento alguno. Nuestra indagación en ese sentido es puramente negativa. Y, por ende, lo más probable es que el principio de aplicación deóntica se baste a sí mismo, y que su único fundamento sea que un ordenamiento que no se rija por esa pauta no es un ordenamiento normativo.

Como muestra de tal indagación infructuosa, vamos a preguntarnos si es lógico reconocer las implicaciones inversas, o sea, si del hecho expresable como " $\mathrm{A} \rightarrow \boldsymbol{o B}$ " podemos razonablemente concluir " $\boldsymbol{o}(\mathrm{A} \rightarrow \mathrm{B})$ ". Llamemos a esa inferencia la "regla de retro-aplicación".(Podríamos someter esa regla a restricciones 
como las del principio de aplicación e incluso más severas, p.ej. que "B" no contenga ninguna ocurrencia de un operador deóntico.)

A primera vista se nos hace raro o enigmático ese procedimiento de retroaplicación. Sin embargo, es absolutamente legítimo preguntarnos si tiene sentido y validez. Si una norma imperativa de contenido implicativo ha de aplicarse (en las acepciones $1^{\mathrm{a}}, 2^{\mathrm{a}}, 3^{\mathrm{a}}$ y $4^{\mathrm{a}}$ ), ¿por qué no vamos a conjeturar que todo lo que pueda objetivamente describirse como una aplicación deóntica lo sea de una norma?

$\mathrm{Si}$ la aplicación de la norma " $\boldsymbol{o}(\mathrm{A} \rightarrow \mathrm{B})$ " estriba en que, ante el supuesto de hecho A, se declare, reconozca o cumpla la obligación de B, entonces, suponiendo que, en presencia del hecho A, se declare, reconozca o cumpla la obligación de $\mathrm{B}$, ¿no podemos colegir que hay una norma, explícita o implícita, expresable como "o $(\mathrm{A} \rightarrow \mathrm{B})$ "? ¿Qué es lo que puede impedir la simetría, hacia atrás como hacia adelante?

Algo que puede impedir la simetría es que no nos hace falta la regla de retroaplicación. La aplicación sí juega un papel importante en la vida normativa de una sociedad, porque, sin ella, la norma "o $(\mathrm{A} \rightarrow \mathrm{B})$ " se quedaría inerme e impotente, no serviría para nada, si, dado el supuesto de hecho A, no se siguiera que hay que cumplir B. Mas lo inverso no es verdad. Si, dado A, hay que cumplir B, no perdemos nada por abstenernos de creer que haya una obligación implicativa de B-en-la-medida-en-que-A.

O sea, esa regla hacia atrás es innecesaria, no juega ningún papel, y sólo sirve a un fin geométrico o estético. Sin embargo, eso todavía no nos dice por qué no podemos admitirla.

Una primera objeción a la regla de retro-aplicación se formularía desde el punto de vista de una lógica relevantista o conexivista y consistiría en exigir que el nexo expresado con la conectiva " $\rightarrow$ " de implicación fuera un vínculo intrínseco y semántico necesario. Así, para excluir la regla de retro-aplicación, podríamos alegar que, aunque, dado el supuesto de hecho de que España tiene más de 40 millones de habitantes (A), es obligatorio que los poderes públicos de Egipto velen por el bienestar de la población (B), no se sigue que sea obligatorio que lo primero implique lo segundo, o que haya una proporción ni nada por el estilo (puesto que jurídicamente son inconexos e independientes); y es que está ahí faltando ese vínculo intrínseco; el "dado que" sería ahí inapropiado, porque más bien se trataría de un "y" (de que A y B).

Respondo que: (1) si ese enigmático vínculo falta en el consecuente, falta en el antecedente, y viceversa; (2) ese vínculo intrínseco es oscurísimo; y (3) de aceptarlo, también la misma regla de aplicación habría de involucrar ese vínculo y no la mera relación fáctica. El tercer motivo es el decisivo. Nuestra regla de aplicación es extensional y no intensional: no involucra ningún arcano, ningún lazo oculto entre prótasis y apódosis, sino una mera proporción de grados de existencia. Así, el art. 1902 CC dice que es obligatorio que, en la medida en que uno, dolosa o imprudentemente, cause daño a otro, repare ese daño ${ }^{6}$. No hace falta ningún nexo de abracadabra entre el daño y la reparación. El nexo obligatorio es meramente de los grados de existencia (del supuesto de hecho del daño doloso o imprudente y de la consecuencia jurídica de la reparación). La regla de aplicación permite, aplicando el art. 1902 CC al supuesto de hecho A, concluir, como consecuencia jurídica, la obligación de la reparación.

Una segunda objeción contra la regla de retro-aplicación sería que tal vez las 
proporciones no son las correctas. Tenemos un supuesto de hecho, A, y una obligación de $\mathrm{B}$; mas quizá no sea cierto que $\mathrm{A} \rightarrow \boldsymbol{B}$, o sea que esté proporcionado el grado de obligatoriedad de $\mathrm{B}$ al grado de realización de $\mathrm{A}$.

Tampoco convence esta objeción, porque podríamos entonces exigir, para que valiera la regla de retro-aplicación, que se diera esa proporción, o sea que sí estuviera sucediendo que A se realizara a lo sumo en la medida en que $\boldsymbol{o B}$. Y ni por ésas va a valer la regla.

Propongo una tercera (y, espero, más convincente) objeción contra la regla de retro-aplicación, a saber: que toda existencia de una obligación adicional requiere una buena razón; a falta de razón, rige el principio jurídico de libertad y, por lo tanto, de licitud (licitud de hacer y licitud de no-hacer).

La obligación responde a una necesidad social, es una ordenación de la razón encaminada al bien común y promulgada por el que tiene a su cargo a la comunidad. Y, así como hace falta, socialmente, la regla de aplicación, no hace falta la de retro-aplicación.

$\mathrm{Y}$ no hace falta porque, en muchos casos, surgirían obligaciones indeseables. Si de que suceda que $A \rightarrow o B$ (e.d., de que se dé la obligatoriedad de $\mathrm{B}$ en un grado igual o mayor que aquel en que de hecho suceda que A), si de eso pudiéramos inferir la obligatoriedad de $\mathrm{A} \rightarrow \mathrm{B}$, ¿se mantendría esa inferencia cuando deje de ser verdad que $\mathrm{A} \rightarrow \boldsymbol{o B}$ ? Está claro que, de mantenerse, se seguirían absurdos (en una serie de casos cuya elaboración imaginativa se deja como ejercicio al lector). Y, de no mantenerse, hay que percatarse de que, entonces, la verdad del consiguiente, $\boldsymbol{o}(\mathrm{A} \rightarrow \mathrm{B})$, es parasitaria respecto a la de $\mathrm{A} \rightarrow \boldsymbol{o B}$ y no enriquece nada en absoluto el acervo jurídico.

Por consiguiente, no vale la regla de retro-aplicación. No es por ahí por donde vamos a poder ir de abajo arriba, además de que, suponiendo que valiera esa regla de retro-aplicación, tampoco nos brindaría una justificación de la aplicación.

\section{Otros intentos fallidos de fundamentación}

Descartada la retro-aplicación, podríamos fuñar en pos de alguna otra fórmula sofisticada y astuta que sirviera de fundamentación al principio de aplicación. P.ej. podemos imaginar que, si vale ese principio, es porque tiene que valer, o sea porque hay una ley no promulgada que nos impone razonar así. Podría ser el principio de implicación lógico-deóntica, PILD, a saber: " $\boldsymbol{o}[\boldsymbol{o}(\mathrm{A} \rightarrow \mathrm{B}) \supset(\mathrm{A} \rightarrow \boldsymbol{o B})]$ ". Usando los axiomas y las reglas de inferencia del sistema LJ bosquejado en el Anejo de este artículo, concluiríamos (con algunas restricciones) que de " $\boldsymbol{o}(\mathrm{A} \rightarrow \mathrm{B})$ " se sigue " $\boldsymbol{o}(\mathrm{A} \rightarrow \boldsymbol{o B})$ ". Es decir, que la aplicación deóntica sería obligatoria.

Mas nos topamos con dos dificultades. La una es que PILD no nos ahorra el principio de aplicación, lo cual significa una pérdida de economía lógica. Y la segunda dificultad es que, usando PILD más el principio de aplicación, de "o $(\mathrm{A} \rightarrow \mathrm{B})$ " concluimos "A $\rightarrow \boldsymbol{o o} \mathrm{B}$ ". Esa conclusión es sumamente inquietante, porque impone nuevas obligaciones (y por ende nuevas prohibiciones). De la obligación de reparar el daño causado, más el supuesto de hecho de haberlo causado, se sigue la obligación de tener la obligación de reparar ese daño. Cualquier obligación condicional (o, más exactamente, implicada por un supuesto de hecho en virtud de una obligación implicativa) acarreará la obligación de tener ese deber (y no sólo de cumplirlo).

Creo que en general ese resultado es indeseable y perturbador. Nos basta con que el causante del daño tenga que indemnizar a la víctima; no queremos 
para nada que, además, tenga que tener que indemnizarla. Si paga, se extingue su obligación de pagar. ¿Se extinguiría también su presunta obligación de tener que pagar? Si no se extingue, la situación resultante es inaceptable; si se extingue, eso parece indicar que era ociosa tal obligación adicional.

No estoy diciendo con ello que sean rechazables todas las reglas que nos lleven a apencar con operadores deónticos iterados. Castañeda pensó que carecía de sentido decir cosas como que una obligación es lícita o es obligatoria o que una autorización lo es ${ }^{7}$. No creo que sea así. Hay un principio de derecho internacional privado que somete el exequatur de una sentencia extranjera a la condición de que "la obligación para cuyo cumplimiento se haya procedido sea lícita en España"8. Tiene perfecto sentido decir que nuestro ordenamiento prohíbe ciertas obligaciones.

Sin embargo, han de ser tasadas y sopesadas las iteraciones que admitamos; hemos de evitar la inflación. Creo que algunas son plausibles, como la de que es lícito todo aquello cuya ilicitud esté prohibida (principio de involutividad deóntica); y que aquello que el ordenamiento jurídico reputa obligatoriamente obligatorio es ya obligatorio; ${ }^{9}$ y que sólo es obligatoria una conducta en la medida en que es lícito que sea obligatoria. En tales casos, hay razones convincentes e independientes a favor de que un operador caiga bajo el alcance de otro en un principio lógico-jurídicamente válido.

No hay razones independientes (o las desconoce el autor de este artículo) para sostener que la obligación condicional de una conducta implique la obligatoriedad de esa obligación (lo cual ya se aproxima peligrosamente a un principio indeseable, "oA $\rightarrow$ oo A": quien tiene que ira la cárcel tiene que tener que ir a la cárcel).
Eso nos hace ver que, a pesar de las cautelas, PILD es una regla inadecuada, que haremos mejor en no abrazar.

Para no alargar este artículo voy a saltar la consideración de otras fórmulas que podríamos pergeñar a título de fundamentaciones del principio de aplicación, advirtiendo únicamente que, de haber alguna enunciación aceptable de tal fundamentación, habrá de colmar los requisitos siguientes: claridad, atractivo, plausibilidad, no ad-hocidad y no agravamiento (o sea, no imponer obligaciones innecesarias).

Al no haber prosperado ni el PILD ni ninguno de los otros principios que hemos barajado y desmenuzado (omito aquí los detalles por motivos de brevedad), no se perfila ningún camino de justificación o fundamentación de abajo arriba por el cual podamos encontrar una regla o un principio más básico que el de aplicación, y que venga a servirle de aval o garantía. Y es que, seguramente, no nos hace falta.

\section{La singularidad lógica del principio de aplicación}

Hay una buena razón para que, de entre los estudiosos de la lógica deóntica, el malogrado Héctor Castañeda haya sido el único (antes de la puesta en pie de nuestros sistemas de lógica juridicial) en asumir principios como el de aplicación (pero también el de retro-aplicación) ${ }^{10}$. Castañeda asumió ese principio porque se percató de su interés práctico (comprendiendo que, sin un principio como el de aplicación, sencillamente las normas implicativas no tendrían aplicación); pero pudo asumirlo porque se basó en una ontología dual de practiciones y de estados de cosas, o hechos. Una practición sería un contenido enunciativo susceptible de acción humana. Lamentablemente hay objeciones fuertes contra esa 
dicotomía (al igual que contra tantas otras), no sólo desde el punto de vista ontológico, o metafísico, sino también desde el punto de vista de la misma aplicabilidad práctica de la lógica deóntica. (No hay más espacio reservable en este artículo para continuar esa discusión.)

La orientación doctrinal de Castañeda siempre fue muy sui generis (como sin duda loes la de nuestra propia lógica juridicial, cuyo sesgo idiosincrásico no pasa desapercibido para nadie.) Las demás escuelas han seguido otros itinerarios, la mayoría de las veces calcando la lógica deóntica sobre un sistema de lógica modal y así leyendo el operador deóntico, "Es obligatorio que" como "Sucede en todos los mundos deónticamente correctos que" (por mucho que esa corrección lo sea desde el punto de vista de un determinado legislador). Ese operador, "o", venía así entendido como el operador de necesidad alético-modal, el cuadrado de las notaciones simbólicas usuales, que a su vez (y en concordancia con la lectura propuesta) guarda estrecha similitud con un cuantificador universal.

En muchos sistemas de lógica cuantificacional (tal vez en casi todos) vale lo que se llama el "principio de desprenexación", nombre que cubre una operación muy sencilla, la que habilita a pasar de un aserto " $\forall x(A \rightarrow B)$ " a otro aserto "A $\rightarrow \forall x B$ " en el supuesto de que en "A"no haya ninguna ocurrencia agazapada (libre) de la variable " $x$ ". Ese principio permite acercar el cuantificador a la parte del enunciado total donde verdaderamente juega su papel, la apódosis "B", puesto que (en la hipótesis dada) a la prótasis "A" no la afecta (es vacua con respecto a ella). Más en general, ese principio es un caso particular de un principio de distribución cuantificacional: " $\forall x(A \rightarrow B) \rightarrow(\forall x A \rightarrow \forall x B) "$. En una serie de lógicas modales (no en todas) tenemos algo similar: si es una verdad necesaria que, si A, B, entonces, si es una verdad necesaria que A, es también una verdad necesaria que B.

En las lógicas deónticas de inspiración modal, se repitió lo propio: " $\boldsymbol{o}(\mathrm{A} \rightarrow \mathrm{B}) \rightarrow(\boldsymbol{o} \mathrm{A} \rightarrow \boldsymbol{o} \mathrm{B})$ ". Ese principio de distribución deóntica es inaceptable en nuestros sistemas de lógica juridicial y es rechazable si la lógica deóntica va a tener un interés para la praxis jurídica. Es obligatorio que, en la medida en que Abrán sea inocente, sea absuelto. Y Abrán tiene obligación de ser inocente. Mas no hay una obligación de absolverlo -si, de hecho, ha quebrantado esa obligación de no-culpabilidad.

Al rechazar el principio de distribución deóntica, nos dimos cuenta de que necesitábamos algo en su lugar; algo mucho más práctico y eficaz, pero sin tales consecuencia deletéreas. Y fue el principio de aplicación. Mas el principio de aplicación suena como algo tremendamente heterodoxo, por no decir paradójico, desde ese paradigma de la lógica deóntica calcada sobre la modal, porque parece mezclar churras con merinas. Dada una norma imperativa de contenido implicativo, $\boldsymbol{o}(\mathrm{A} \rightarrow \mathrm{B})$, nos habilita a concluir que un mero supuesto de hecho, A,implica una consecuencia normativa, $\boldsymbol{o B}$. O sea, que los hechos influyen en los derechos, en vez de que lo fáctico y lo normativo habiten en sus respectivos mundos, el sublunar de lo que sucede o deja de suceder y el celestial de lo que debe o no debe suceder (por mucho que ese deber sea relativo a los mandatos de un legislador determinado) ${ }^{11}$.

La visión separatista de lo fáctico y lo normativo fue característica, claro está, de casi toda (o de toda) la lógica deóntica que se ha construido fuera de nuestra particular escuela de lógica juridicial; pero también ha sido asumida sin pestañear por el normativismo de Kelsen, en cuyo sistema juega el papel de 
una presuposición insoslayable, sin la cual se derrumbaría la propia empresa teorética del normativismo ${ }^{12}$.

Justamente es un rasgo original de nuestra escuela de lógica juridicial haber superado esa separación ${ }^{13}$. Lo fáctico y lo normativo se influyen ${ }^{14}$. Eso es lo que da pie a la aplicabilidad de las normas jurídicas, a saber: que las situaciones jurídicas existentes dependen no sólo de los preceptos del legislador (y de principios jurídicos no promulgados, sin los cuales no puede sostenerse un sistema normativo mínimamente congruente $\mathrm{y}$ completo), sino también de qué hechos acaezcan o dejen de acaecer.

\section{El nexo entre lo normativo y lo fáctico}

Una objeción contra el principio de aplicación que se nos ha formulado es que, si la norma imperativa de contenido implicativo más un supuesto de hecho entrañan la existencia de una situación jurídica, entonces, por modus tollens, esa norma más otra situación jurídica(justamente su contradictoria) entrañan una consecuencia fáctica. O sea -continúa el objetor-que podemos saber qué pasa en la realidad simplemente sabiendo qué debe o no-debe pasar. Y eso abre una curiosa vía de indagación de la realidad empírica, a saber: escrutar las situaciones jurídicas.

Contesto que efectivamente es así: dada una cierta combinación de situaciones jurídicas, es seguro que también se están dando, o se han dado, unos supuestos de hecho. Y eso es así porque, de no darse (en absoluto) esos supuestos de hecho, tampoco serían ésas las situaciones jurídicas.

Así, volvamos al art. 1902 CC: es obligatorio que, en la medida en que uno -digamos Diego-, mediante culpa o negligencia, cause un daño a otro -digamos
Celedonio-, repare el daño causado. Supongamos la siguiente situación jurídica, a saber: que le es lícito a Diego no pagar nada a Celedonio. De ese par de premisas, ambas normativas, podemos inferir una conclusión fáctica: que Diego no ha causado ningún daño a Celedonio (o, si le ha causado un daño, será uno de caso fortuito o fuerza mayor, o sea uno en el que no hayan intervenido para nada ni mala intención ni descuido reprobable).

- Mas ¿no es como un milagro que de lo normativo salga lo fáctico? ¿Qué varita mágica tiene lo normativo para subvertir los hechos (como el poderoso amor tiene, para Juan de Mena, maneras para trastornar la fe)?

- No hay ningún milagro. Lo que pasa es que el surgimiento de una determinada situación jurídica -concretamente el estar libre Diego de tener que pagar nada a Celedonio- depende de la concurrencia de un supuesto de hecho, a saber: el de que Diego no haya causado daño a Celedonio con dolo o imprudencia.

- Objeción: no es así. Puede que le haya causado el daño, pero se haya extinguido ya la obligación de pagar, sea porque el propio Diego haya satisfecho la indemnización o porque lo haya hecho un tercero ${ }^{15}$.

- Evidentemente, el precepto del CC hay que interpretarlo adecuadamente. 'Haber causado un daño con culpa o negligencia' ha de leerse en el sentido de 'un daño no reparado'. Si el pago propio o ajeno extingue esa deuda, ello significa que la norma que, para abreviar, hemos expresado como lo hemos hecho (parafraseando al CC) habría de enunciarse, por mor de exactitud, de manera más compleja (algo así como: es obligatorio que el que cause daño a otro, 
interviniendo culpa o negligencia, sin que ese daño esté reparado, repare el daño). Sea como fuere, para nuestro actual propósito eso es secundario; lo esencial es que de un manojo de normas y situaciones jurídicas se sigue la factualidad de unos hechos, aunque sea una factualidad disyuntiva (la de que o Diego no ha causado el daño, o ha sido por fuerza mayor, o ya ha indemnizado u otro ha terciado pagando por él). ${ }^{16}$

\section{Aplicación y subsunción}

En nuestro análisis del principio de aplicación nos hemos referido ya a la subsunción, pero ésta conlleva algunas complicaciones y dificultades que hemos de abordar.

Estamos en presencia de una norma de contenido implicativo también cuando aquello que tenemos delante es una cuantificación universal de una fórmula así. O sea, son, para nuestro propósito, también normas de contenido implicativo las del tipo " $\forall \mathbf{x} \boldsymbol{o}(\mathrm{A} \rightarrow \mathrm{B})$ ".

Hay fórmulas cuantificacionales de otro tipo conexo, las " $\boldsymbol{\forall} \forall \mathbf{x}(\mathrm{A} \rightarrow \mathrm{B})$ ". Mas éstas suscitan unas dificultades adicionales, que se les han escapado a quienes (adictos a los paradigmas de la lógica deóntica estándar) han creído, equivocadamente, en el principio de simplificación deóntica (a saber que es válido “ $\boldsymbol{o}(\mathrm{A} \wedge \mathrm{B}) \rightarrow \boldsymbol{o} \mathrm{A} ")$. No es así: la obligación deadoptar a los dos hermanos gemelos (en un supuesto de hecho de haber adquirido ese compromiso) no implica la de adoptar al uno si uno se abstiene totalmente de adoptar al otro, porque el cumplir nada más con un conyunto es peor que no cumplir con ninguno. Dado que un cuantificador universal es como una conyunción potencialmente infinita o indefinida, la obligación de que todos tengan una conducta no implica la de cada uno a tener esa conducta hagan lo que hagan los demás, porque la obligación individual de conducta puede estar condicionada al cumplimiento de los demás, o de varios o muchos de ellos.

Pues bien, supongamos una norma cuantificacional, " $\forall x \boldsymbol{x}(\mathrm{A} \rightarrow \mathrm{B})$ ". Y ahora supongamos un hecho, C. Subsumir C en el supuesto general de hecho de dicha norma estriba en percatarse de que $\mathrm{C}$ es una instancia de A. P.ej., si "A" es "uno agrede a otro", C puede ser "Pompeyo agrede a César". Las operaciones más sencillas de subsunción no pasan de ser un ejercicio de primer trimestre del primer año de iniciación a la lógica, pero a nadie se le oculta que, en la práctica, hay que acudir a muchas paráfrasis, reformulaciones e interpretaciones para obtener formulaciones que se plieguen satisfactoriamente a esa aplicación (que tiene algo de plegamento o de regimentación).

Así pues, esa subsunción por mera singularización conlleva una operación intelectual que no es la mera constatación de $\mathrm{C}$, sino la averiguación de que $\mathrm{C}$ es un caso de A; averiguación sencillísima en los ejemplos escolares y que se va haciendo ardua o dudosa en la vida forense (aunque esperamos que los árboles no nos impidan ver el bosque).

Pero la verdadera subsunción compleja se da cuando lo que se constata es $\mathrm{D}, \mathrm{y}$ hace falta una operación intelectual más complicada para determinar que $\mathrm{D}$ es $\mathrm{C}$ y, por lo tanto, un caso de $\mathrm{A}$.

Así, volvemos a nuestro ya manido art. 1902 del CC: toda persona está obligada a, en la medida en que, culposamente, cause daño a otra, indemnice ese daño. Constatamos D, a saber: que Isidro ha dejado bloqueado a Ignacio en la estación de tren (por una negligencia a la hora de conectar la electricidad de los tornos) y, así, Ignacio, que iba a pasar un concurso de acceso a una plaza de profesor titular con buenas esperanzas, no ha 
podido hacerlo, de resultas de lo cual ha sufrido un grave lucro cesante (más quizá daño emergente, como puede ser una depresión nerviosa y la ruptura con su novia).

La situación así descrita, D, ¿es un caso de $\mathrm{C}$, o sea de que tal persona concreta, Isidro, cause a otra, Ignacio, un daño por culpa o negligencia, y que ese daño sea la sucesión de desgracias más lo que Ignacio dejará de ganar? Para responder afirmativa o negativamente hay que hacer un razonamiento deductivo, en el que se aducirán premisas mayores, que siempre pueden ponerse en duda. Cada extremo de la descripción puede ser objeto de discusión. Mas, admitidos los hechos que hemos supuesto, D, generalmente concordaríamos en que se trata de un caso particular de un causar daño imprudente o negligente (aunque la noción de negligencia tiene unas notas normativas). O sea, por esa operación de subsunción llegamos a la conclusión de que D es C. Y así, C es un A; por aplicación lógico-juridicial, resulta obligatorio que $\mathrm{E}$, donde $\mathrm{E}$ es que Isidro (en concreto) indemnice (en concreto) a Ignacio, lo cual es una instancia de $B$ (subsumible en B en tanto en cuanto D lo sea en A).

De hecho la subsunción es más complicada, porque ha de tratarse de indemnizar ese daño, lo cual determina que la formalización adecuada involucraría otra cuantificación, en la que el campo de variación serían efectos dañinos, p.ej.; creo que es lícito prescindir aquí de tales complicaciones, porque no estamos ante un ejercicio preciso de formalización lógico-jurídica.

Todas esas complicaciones no son óbice al principio de aplicación, sino justo al revés: sólo tienen sentido en la medida en que vengan a modular las aplicaciones del principio de aplicación.

Sin un principio o una regla que esté en la cercanía de nuestro principio de aplicación, no se ve de qué servirían las operaciones de paráfrasis, interpretación y subsunción directa o indirecta. Todo eso sirve de algo y juega un papel en la vida jurídica si hay un principio o una regla de lógica jurídica que nos habilite para desplazar el operador deóntico de obligación de la fórmula implicativa total a la apódosis, una vez que tenemos el supuesto de hecho -la prótasis- que hemos conseguido determinar gracias a esas operaciones subsuntivas y anejas.

\section{La obligación de cumplir la norma vigente}

Las reflexiones de anteriores apartados nos han llevado a ser escépticos con respecto a la posibilidad de hallar una fundamentación o una justificación de las operaciones aplicatorias, o sea las que figuran como acepciones $1^{\mathrm{a}}, 2^{\mathrm{a}}, 3^{\mathrm{a}}$ y $4^{\mathrm{a}} \mathrm{de}$ la aplicación normativa (según se presentaron en el 2). Sin embargo, tal vez la busca era innecesaria. Para dividir la dificultad, empezamos por lo más fácil, que es ver si efectivamente hace falta alguna justificación especial en lo tocante a la aplicación en las acepciones finales, en aquellas en las que aplicar es cumplir, o sea la $2^{\mathrm{a}}$ y la $4^{\mathrm{a}}$.

Veámoslo primero con la $4^{\mathrm{a}}$. Suponemos la norma $\boldsymbol{o}(\mathrm{A} \rightarrow \mathrm{B})$ y el supuesto de hecho A(o uno que hemos subsumido en A). Y se trata ahora de aplicar en el sentido de cumplir; o sea, dando ya por descontada la aplicación en la acepción $3^{\mathrm{a}}$, el obligado tiene que dar el último paso de la aplicación, que es cumplir. Cumplir ¿qué? ¿Cuál obligación concreta se trata de que cumpla? Cualquiera de las dos obligaciones: sea la implicativa, $\boldsymbol{o}(\mathrm{A} \rightarrow \mathrm{B})$, sea la consecuencia jurídica, $\boldsymbol{o B}$ (dado el supuesto de hecho A). Para cumplir sólo tiene que hacer una cosa: B.(Dejo de lado la complicación de que tiene que hacer un poco más, a saber: $B$ en una 
medida igual o superior a aquella en que sucede que A). Realizando la conducta $\mathrm{B}$, el agente de quien se trate a la vez realiza $\mathrm{A} \rightarrow \mathrm{B}$ (con esa salvedad sobre los grados de realización). No hay, pues, ninguna obligación adicional de cumplir la norma vigente; basta con la norma vigente, que es una norma imperativa.

La obligación de aplicar la vigente norma jurídica, $\boldsymbol{o}(\mathrm{A} \rightarrow \mathrm{B})$, por lo tanto, se reduce, en esa acepción $4^{\mathrm{a}}$, a la propia norma más la existencia del supuesto de hecho, lo cual determina la existencia de la situación jurídica $\boldsymbol{o B}$. Cualquiera de las dos normas, la abstracta y general, $\boldsymbol{o}(\mathrm{A} \rightarrow \mathrm{B})$, y la concreta y particular, $\boldsymbol{o B}$, determinan ya de suyo la conducta que el obligado tiene que hacer.

El caso de la acepción $2^{\mathrm{a}}$ es un poco más difícil, porque el juez o la autoridad administrativa en cuestión tiene ahí que ejecutar o hacer ejecutar la obligación previamente constituida o declarada en un acto jurídico. ¿De dónde sale esa obligación de ejecución? No hemos hallado ningún principio o fundamento más básico, pero tal vez no nos haga falta. La obligación de ejecución la impone en ese caso el ordenamiento jurídico como una obligación adicional, para no dejar las decisiones que crean o declaran situaciones jurídicas en papel mojado. Aquí nos encontramos con una meta-regla, o una regla metajurídica, que vincula la validez o vigencia del derecho con su eficacia. Para el propio Kelsen un ordenamiento jurídico amplia y duraderamente ineficaz cesa de existir (es la pequeña hendidura que él deja en su tabique separador de lo fáctico y lo normativo).

Desde una perspectiva como la aquí defendida, en la cual lo fáctico y lo normativo se hibridan entre sí, una norma persistentemente ineficaz es abrogada o de hecho nunca entra en vigor. Nuestro enfoque de entremezcla fáctico-normativa se casa muy bien con el democratismo jurídico de Joaquín Costa, para el cual el pueblo es siempre un co-legislador. Para que una ley adquiera vigencia y la mantenga, es menester el consentimiento popular (aunque sea bajo coacción, o sea no-libre). El promulgador de la norma (o, más bien, del precepto) la somete $a d$ referendum. ${ }^{17}$

Sabido lo cual, el legislador tiene la tarea de velar para que no se queden ineficaces ni las normas generales ni las concretas (un fallo es una norma singular y concreta). O sea para que se cumplan. Y por eso es tarea de los órganos administrativos y jurisdiccionales -según las pautas procedimentales que sean del caso- mandar y hacer ejecutar las decisiones en las que se han establecido o declarado situaciones jurídicas; o sea, hacer cumplir las normas. Esa acepción $2^{\mathrm{a}}$ es, pues, la de aplicar, no en el sentido de cumplir, pero sí en el de hacer cumplir (que a su vez es un cumplimiento de otra norma, aquella que impone al juez o al funcionario administrativo una tarea de hacer ejecutar la decisión previamente adoptada.)

Pasamos a la acepción $3^{\mathrm{a}}$. Aquí no necesitamos tampoco ninguna obligación. La mera lógica jurídica pasa de la obligación implicativa $\boldsymbol{o}(\mathrm{A} \rightarrow \mathrm{B})$, dado el supuesto de hecho A, a la obligación $\boldsymbol{o B}$. No hace falta ninguna obligación de pasar. Es obra de la propia lógica, es obra de la naturaleza misma de las cosas, que, dada la obligación implicativa y dado el supuesto de hecho A, se siga la obligación $\boldsymbol{o B}$, y eso tanto si el obligado lo sabe como si lo ignora, tanto si le conviene como si no, tanto si le gusta como si le desagrada, tanto si lo reconoce como si se llama andana.

De todos modos, ya vimos que de poco serviría buscar una obligación más fundamental de razonar con lógica, porque un Aquiles interesado en no alcanzar a la tortuga siempre podrá alegar que, a 
sabiendas de todo eso, no llega a la conclusión, porque le haría falta un paso previo (una meta-regla de inferencia, y antes una meta-meta-regla y así al infinito).

Nos queda, pues, la acepción $1^{\mathrm{a}}$. Y aquí, de nuevo, mal haremos en buscar un fundamento lógico. Dado un supuesto de hecho y dada una obligación de contenido implicativo, el fundamento de la obligación del juez de declarar o crear una situación jurídica no viene de otra fuente que de un mandato adicional del ordenamiento jurídico, que le impone esa obligación.

Desde luego, el ordenamiento lo hace con una buena razón, en todos aquellos casos en los que la subsunción es problemática y sujeta a controversia (ya sea por el mero reconocimiento de los datos fácticos, ya sea por su subsunción y calificación jurídica) o en los que el juez ha de actuar con un poder arbitral, lo cual significa que, entonces, entre los supuestos de hecho está la convicción del juzgador de la justicia de la decisión arbitral. (P.ej. en un divorcio, la condena concreta al pago de una pensión compensatoria determinada, dados los hechos y dada la normativa aplicable). Sería vano buscar ese poder jurisdiccional en otra fuente que en aquellas normas procesales que impongan esos deberes al juez.

Eso sí, el legislador ha establecido tales normas procesales para que las normas se apliquen (en todos los sentidos) $\mathrm{y}$, por lo tanto, a la postre, se cumplan, porque forma parte de su misión como legislador hacer que se cumpla la ley (y no sólo que ésta corresponda en su redacción a un ideal de justicia).

\section{El principio de Hamurabí y la obligación de cumplir}

Nuestra reflexión precedente nos ha llevado a conclusiones económicas, prescindiendo de una obligación adicional de aplicar la norma, salvo en los casos en que, por tratarse de una aplicación en las acepciones $1^{\mathrm{a}}$ o $2^{\mathrm{a}}$, hay otra norma -generalmente procesal- que impone la aplicación como medio para el fin del cumplimiento.

Pero, puesto que, a la postre, aplicar es cumplir (o dar pasos que son menester para el cumplimiento), la obligación de aplicar la norma jurídica vigente podríamos buscarla (y será un último intento) en otra norma implicativa de carácter general, que muchas veces encontramos dispersamente formulada en los códigos.

Los compiladores o codificadores suelen tener la preocupación de que los sujetos jurídicos se percaten de que lo así compilado es una norma, tiene fuerza de obligar, y por eso añaden frecuentemente una cláusula adicional que viene a decir algo así como que hay que aplicar todo lo que manda el código. Una cláusula que puede leerse ya (si nos otorgamos una cierta libertad de paráfrasis) en el Código de Hamurabí, por lo cual voy a bautizar así este principio normativo, que establecería esa obligación: $\boldsymbol{o}(\boldsymbol{o} \mathrm{A} \rightarrow \mathrm{A})$.

Los sistemas de lógica deóntica estándar no solieron recoger el principio de Hamurabí en su arsenal deductivo, aunque alguno sí lo hizo. En los modelos kripkeanos asociados a esas lógicas se formuló la condición adecuada para que se cumpliera ese axioma, de lo cual podemos prescindir aquí (puesto que, de todos modos, esos modelos se quiebran en nuestra construcción en la cual lo normativo depende en parte de lo fáctico, según lo hemos expuesto más arriba).

El principio de Hamurabí añade, para cada obligación legal, oA, una obligación adicional, $\boldsymbol{o}(\boldsymbol{o} \mathrm{A} \rightarrow \mathrm{A})$. Ese principio suena a vacua tautología, y no lo es. Podríamos enunciarlo en román paladino como "Se debe hacer lo que se debe hacer" y tal formulación acentúa ese aire 
de tautología. Fíjese, empero, el lector en que el análisis de tal enunciado es éste: "Se debe hacer esto: hacer lo que se debe hacer" (y no "Lo que se debe hacer se debe hacer", o sea "oA $\rightarrow$ oA"). Es como, en lo alético-modal, decir que necesariamente lo necesario sucede (que no es lo mismo que decir que lo necesario es necesario).

Pero ¿sirve de algo el principio de Hamurabí? Sí sirve, mas sirve demasiado. El primer servicio que podríamos buscar es que, identificando (para simplificar) la aplicación con el cumplimiento de la ley, lo que nos dice este principio es que hay que aplicar la ley. $\mathrm{O}$ sea, este principio nos brindaría un fundamento puramente lógico-jurídico de por qué hay que aplicar la ley, a saber: que ello es una verdad del sistema correcto de lógica jurídica.

Además, el principio no carece de atractivo. Su aire incluso de tautología cuando uno lo escucha por primera vez es un indicio de que, lejos de parecer abstruso o chocante, da la impresión de una obviedad, como corresponde a las verdades lógicas (que son obvias hasta que dejan de serlo al vérseles el intríngulis). Conque su aparente inserción en los códigos podría explicarse como una llamada de atención del legislador, que estaría meramente recordando una verdad de Pero Grullo, de esas que, de puro sabidas, corren el peligro de olvidarse.

Filosóficamente podemos justificar el principio de Hamurabí analizando lo que dice: lo que dice es, equivalentemente, $\boldsymbol{o}(\mathrm{A} \rightarrow \boldsymbol{l} \mathrm{A})$ (donde la ' $\boldsymbol{l}$ ' es el operador de licitud, evidentemente definido " $l$ A" como " $\boldsymbol{O} \sim \mathrm{A}$ ", o sea la licitud es la no prohibición). Y así formulado vemos que lo que se está diciendo es que es obligado no hacer una cosa más que en la medida en que sea lícita; abstenerse de hacerla en la medida en que esté prohibida.
Una objeción contra el principio de Hamurabí es que su atractivo inicial se esfuma cuando lo leemos hacia atrás; lo que nos está diciendo, visto así, es que es obligatorio que una obligación exista sólo en la medida en que se cumpla. O sea, el principio está imponiendo a cada obligación jurídica un deber metajurídico, el de obligar sólo en la medida en que se cumpla de hecho la obligación. Y no deseamos que un principio lógico sujete a las obligaciones jurídicas a ese constreñimiento, que significaría que la norma tiene que ajustarse a las situaciones fácticas y no al revés.

Sea ello como fuere, una razón decisiva para repudiar el principio de Hamurabí es que, junto con otros principios y reglas de nuestra lógica juridicial, acarrea una consecuencia inadmisible, a saber: que todo hecho existente es lícito ("A $\rightarrow \boldsymbol{l A}$ "). Para obtenerlo usamos, primero, el principio de aplicación $[\boldsymbol{o}(\mathrm{A} \rightarrow \mathrm{B}) \supset(\mathrm{A} \rightarrow \boldsymbol{o} \mathrm{B})]$; y luego el principio de involutividad deóntica ("olA $\rightarrow \boldsymbol{l A}$ ": lo obligatoriamente lícito es lícito; o, con otras palabras: lo obligatorio es lícitamente obligatorio: "oA $\rightarrow$ loA"). $\mathrm{Ni}$ siquiera podríamos bloquear esa conclusión exigiendo para "A", en el principio de Hamurabí, que no hubiera ninguna ocurrencia de ningún operador deóntico (que "A" fuera puramente fáctica). Esta razón es decisiva. O está mal el principio de aplicación (sin el cual las normas son inaplicables), o lo está el de involutividad deóntica (sin el cual habría obligaciones ilícitas) o hay que decir adiós al principio de Hamurabí. Y esto último es lo que haremos.

Para rematar esta discusión del principio de Hamurabí, diré que la introducción de obligaciones adicionales tiene siempre que estar justificada, en virtud de la suprema regla de libertad, a saber: que lo que no haya buenas razones para que esté prohibido ha de estar permitido 
(una regla que preside toda nuestra construcción tanto en el plano jusfilosófico como en el formal). Si hay tantos motivos de sospecha frente al principio de Hamurabí -que ciertamente impone un fardo deóntico adicional-, hay (en la duda) un buen motivo para no asumirlo.

\section{La aplicación de normas permisivas}

Si las lógicas deónticas estándar ya carecían de un principio de aplicación deóntica (cuya carencia apenas compensaban con el principio de distribución deóntica), más alejadas todavía estaban de considerar la validez de principios distributivos, o similares, en los que el operador prefijado a la fórmula implicativa fuera el de licitud. Por el contrario, la lógica juridicial (puesta en pie por el equipo JuriLog) recoge en su arsenal deductivo principios en los cuales el operador de licitud es el que gobierna la fórmula implicativa antecedente; en realidad $-\mathrm{y}$ sin hacer ningún dogma de tal paridadesta lógica tiende a establecer un cierto paralelismo entre las inferencias que involucran a los dos operadores, el de obligación y el de licitud.

Llamaré 'principio de aplicación permisiva' a éste: " $l(\mathrm{~A} \rightarrow \mathrm{B}) \supset[\mathrm{A} \rightarrow \boldsymbol{B}]$ ]". Es un principio exactamente paralelo al principio de aplicación deóntica, o principio de aplicación a secas (por antonomasia).

Este principio de aplicación permisiva se presta a una partición similar a la del principio de aplicación deóntica. En unos casos, el derecho a la conducta o prestación B se deduce directamente del supuesto de hecho A cuando tiene vigencia la norma permisiva $l(A \rightarrow B)$, una norma que autoriza a la conducta $B$ en la medida en que se esté dando el supuesto de hecho A. Cuando es palmaria la constatación de ese supuesto de hecho, A, cualquier sujeto de derecho afectado está así lógicamente habilitado a concluir que le es lícita la conducta B (o que tiene derecho a la prestación B). En los casos en que el legislador sabe que esa constatación es problemática, controvertible, o que requiere una subsunción y calificación jurídica, reserva a ciertas personas (públicas o privadas) la potestad de establecer que se da el supuesto de hecho y, por consiguiente, declarar la situación jurídica expresable como " $l \mathrm{~B}$ ".

Sin embargo, la gran diferencia entre los dos principios es que una obligación se cumple y una permisión se ejerce o se disfruta. Y no es obligatorio ejercerla. El titular del derecho en cuestión, el sujeto activo de la norma permisiva " $l(\mathrm{~A} \rightarrow \mathrm{B})$ ", al constatar $\mathrm{A}$, puede saberse con derecho a B. Si efectivamente realiza esa conducta, B, ejercita tal derecho, mas no cumple nada. Eso hace que, de cara a los destinatarios finales del derecho, el principio de aplicación permisiva no pueda tener la misma relevancia jurídica que su hermano gemelo, el principio de aplicación deóntica.

Muy distinto es el caso con respecto a la administración, a los tribunales y a aquellos particulares que, en su ámbito de actividad privada, ejerzan alguna función de autoridad. Porque a ellos incumbe, ante la norma permisiva " $l(\mathrm{~A} \rightarrow \mathrm{B})$ " $\mathrm{y}$ ante la existencia del hecho $\mathrm{A}$, declararla situación jurídica " $l \mathrm{~B}$ ", y concomitantemente los deberes ajenos de no-vulneración (por el principio lógico-jurídico de no impedimento, que ampara el ejercicio de cualquier derecho frente a intromisiones ajenas). Y, declaradas las obligaciones ajenas de no impedimento, eventualmente se pasa a la acepción $2^{\text {a }}$ : hacer que se ejecuten.

Cuando la norma establece que es lícito, para cualquiera que alcance los 18 años y sea español, votar en las elecciones generales, se sigue -por pura lógica jurídica- que la constatación del supuesto de 
hecho de que Asunción ha alcanzado los 18 años y es española acarrea un derecho suyo a votar, que incumbe a los funcionarios tomar en cuenta y respetar (con la oportuna inscripción en el censo electoral y sus consecuencias jurídicas).

Notemos, para cerrar ya este apartado, que en la vida jurídica se dan iteraciones y encabalgamientos de operadores. El ordenamiento jurídico no sólo otorga a cada uno el derecho a, en la medida en que alcance esas condiciones, votar, sino que lo establece como un derecho obligado (lo cual no significa un derecho de ejercicio obligatorio, que pasaría a ser un derecho-deber, una obligación). Podemos formularlo como "ol $(\mathrm{A} \rightarrow \mathrm{B})$ ". Es un derecho, pero además es obligatorio que exista tal derecho (lo es porque así se lo impone la constitución a la propia ley electoral). Usando sucesivamente los dos principios de aplicación obtenemos: "A $\rightarrow$ olB". Quien reúna esas condiciones forzosamente es titular del derecho de voto. En los casos en los que el reconocimiento de la prótasis, $\mathrm{A}$, tiene que superar una controversia $y$ necesita una oportuna y autorizada calificación jurídica, será competencia del juez zanjar y, a fuer de tal, decidir la consecuencia jurídica, "olB", o sea el inviolable derecho de voto de la persona en cuestión.

\section{El principio de limitación}

Sabemos que hay una regla metajurídica válida (en virtud del principio jusfilosófico de libertad) que es como un principio occamiano de economía: las obligaciones no deben multiplicarse sin necesidad. Eso nos hizo descartar más arriba el principio de retro-aplicación, “( $\mathrm{A} \rightarrow \boldsymbol{o} \mathrm{B}) \supset \boldsymbol{o}(\mathrm{A} \rightarrow \mathrm{B})$ ".

Mas, en cambio, la permisión se presume (por la regla de libertad); y, por lo tanto, no se oponen tales obstáculos a la aceptación de un principio de retro-aplicación permisiva, " $(\mathrm{A} \rightarrow \boldsymbol{l} \mathrm{B}) \supset \boldsymbol{l}(\mathrm{A} \rightarrow \mathrm{B})$ ". Lo llamaré 'principio de limitación'.

Ese principio parece perfectamente asumible en una reelaboración de nuestra lógica juridicial. Es equivalente a este otro: " $(\boldsymbol{o} A \rightarrow \mathrm{B}) \supset \boldsymbol{l}(\mathrm{A} \rightarrow \mathrm{B})$ ". Y lo que viene a decirnos es que, cuando la obligación de realizar una conducta no supera un cierto grado, es lícito que esa conducta se realice sólo hasta ese grado y no más. $\mathrm{O}$, alternativamente, que, cuando, en la medida en que se reúnan ciertas condiciones, se tiene derecho a realizar una conducta, se tiene también derecho a esto: realizar esa conducta en la medida en que reúna uno esas condiciones.

En el nuevo sistema de lógica juridicial, LJ, propuesto en el Anejo de este artículo ese principio de limitación se deduce, como teorema, de la ley del mismo nombre. En ese sistema, la diferencia (que convencionalmente adopto) entre leyes y principios estriba en que las leyes son verdades deónticas, o sea son normas no promulgadas, que se incorporan al ordenamiento jurídico independientemente de la voluntad del legislador. Mas de esa ley de limitación sale su principio homónimo, con ayuda del principio de aplicación permisiva.

Como instancia de este principio podemos poner la siguiente. Supongamos que, en la medida (al menos) en que Madagascar se abstiene del armamento atómico, tiene derecho al uso de energía nuclear; de ahí se sigue (por dicho principio) que le es lícito lo siguiente: usar energía nuclear en tanto en cuanto se abstenga del armamento atómico.

Entre los supuestos de hecho puede haber estados de cosas normativos. Lo fáctico no excluye lo jurídico, ya que un hecho puede ser normativo o no (e, incluso -cuando no es propia o estricta- 
mente normativo- puede comportar una descripción con notas normativas). De ahí que una instancia del principio de limitación sería ésta: En la medida en que permanezca en vigor la ley de arrendamientos urbanos, o LAU, el casero puede subir periódicamente el alquiler al inquilino; luego es lícito que, en tanto en cuanto siga vigente esa ley, el casero incremente periódicamente el alquiler. Vemos en qué sentido se trata de una retro-aplicación, o aplicación al revés. No tratamos de averiguar si el casero tiene derecho a subir el alquiler, sino que partimos de que así es, en tanto en cuanto siga en vigor la actual LAU. Lo que buscamos es una permisión de contenido implicativo que se deduzca de la situación fáctico-jurídica dada.

La validez de esa retro-aplicación permisiva nos hace cuestionarnos en qué dirección funcionan aquí la subsunción y la calificación jurídica. Si introducimos cuantificadores, veremos que la subsunción aquí puede ir de la prótasis a la apódosis, a pesar de que ésta tiene un contenido implicativo y, por lo tanto, mayor vocación de generalidad. Un ejemplo de lo cual sería: "Si, en la medida en que esté soltero, Leandro puede formar pareja con un adulto (que lo desee, siempre que no haya otro impedimento), entonces es lícito que, en tanto en cuanto siga soltero, Leandro se case el año que viene con Juana", suponiendo la ausencia de impedimentos dirimentes. Casarse es un concepto subsumible bajo el de formar-pareja -bajo el cual sería también subsumible el de constituir una unión de hecho.

Así pues, la retro-aplicación no deja de ser en cierto modo, una aplicación o concreción, en tanto en cuanto puede comportar los momentos de la subsunción y de la calificación.

\section{Objeción: ¿hay normas inaplicables?}

Siendo el meollo de este artículo la defensa y dilucidación de los dos principios de aplicación -el de aplicación deóntica y el de aplicación permisiva-, hemos de afrontar la objeción que rechaza vincular lo lógico y lo jurídico, a la cual aún no hemos contestado suficientemente. ${ }^{18}$

En virtud de esos principios, si tenemos " $\boldsymbol{o}(\mathrm{A} \rightarrow \mathrm{B})$ " podemos concluir "A $\rightarrow$ o B", y, si tenemos " $l(A \rightarrow B)$ ", podemos concluir " $\mathrm{A} \rightarrow \boldsymbol{l B}$ ".

Vamos a tomar una instancia del principio de aplicación permisiva. Mediante modus tollens, del par de premisas " $l(\mathrm{~A} \rightarrow \mathrm{B})$ " $\mathrm{y}$ " $v \mathrm{~B}$ ", podemos concluir " $\sim \mathrm{A}$ ".

Pues bien, una de dos: o bien la promulgación legislativa es una condición suficiente para la vigencia de una norma o no lo es. No se está diciendo que sea una condición necesaria. Admitimos que hay normas no promulgadas (derecho natural o -si se quiere- conjunto de normas válidas en virtud de la naturaleza misma de la materia jurídica y de la lógica de las normas). Lo único que se está cuestionando es si es suficiente para la vigencia de una norma su promulgación (correctamente hecha) del legislador (de quien, en la comunidad dada, está investido de la potestad legislativa) -junto con el hecho de que no haya sido ulteriormente abrogada.

Aceptemos que es, en efecto, una condición suficiente esa promulgación. El legislador promulga dos normas, una de las cuales establece la situación jurídica " $l(\mathrm{~A} \rightarrow \mathrm{B})$ ", al paso que la otra establece "vB" (o sea “o B"). O sea, el legislador, en un precepto, está autorizando que, en tanto en cuanto suceda que $A$, se efectúe $\mathrm{B}$; y en otro precepto prohíbe $\mathrm{B}$. Eso estará bien o estará mal, suscitará un 
conflicto normativo o no, pero suceden casos así. En virtud del principio de aplicación permisiva, concluimos " $\mathrm{A}$ ". $\mathrm{O}$ sea, ha bastado la actividad legislativa para producir una situación de hecho que puede no tener nada de jurídico -donde A puede consistir en un hecho puramente fáctico y extra-normativo, como que un individuo tenga más de 18 años de edad, o que haya sequía.

Como eso no es posible (el legislador no puede cambiar la edad real de los individuos ni la existencia de sequías, sino sólo sus efectos jurídicos), hay que concluir que, si vale este principio de aplicación permisiva, el promulgamiento legislativo no es condición suficiente para la vigencia de una norma.

Contesto que así es. El legislador no puede, con su solo acto legislativo, determinar la obligatoriedad, prohibición o licitud de una conducta (ni, menos aún, el grado, respectivamente, de tal obligación, prohibición o licitud), independientemente de la existencia de otras normas jurídicas previamente promulgadas y de la situación real en el mundo. Siendo la promulgación un acto jurídico, tiene también sus condiciones de validez. En determinadas condiciones es nulo.

$\mathrm{Si}$, habiendo promulgado ya la licitud de $A \rightarrow B$, y sucediendo que, de hecho, $A$ sea un estado de cosas plenamente realizado (hipótesis), el legislador emite un acto jurídico de prohibición de $\mathrm{B}$, este último es nulo (a menos que conlleve una abrogación de la norma bajo la que se subsuma la licitud de $A \rightarrow B$ ).

Esa condición de validez es sencilla: es nulo un acto jurídico creador de una situación jurídica totalmente incompatible con una situación fáctica.

De lo cual sacamos la conclusión (concorde con nuestro jusnaturalismo) de que la promulgación no es ni condición necesaria de validez de todas las normas (aunque sí de la mayoría de ellas) ni condición suficiente.

La recién alcanzada conclusión sobre el promulgamiento se extiende a cualquier otro acto jurídico, público o privado, creador de una situación jurídica totalmente incompatible con una situación fáctica (con un hecho existente), como puede ser una sentencia judicial, un reglamento, una orden administrativa, un testamento, un contrato. Desde luego, por el principio de conservación del acto, siempre habrá de reducirse la nulidad a lo mínimo indispensable -en tanto en cuanto pueda conservarse el resto de lo dispuesto en el acto prescindiéndose de la cláusula nula-. ${ }^{19}$

$Y$ es que el problema no afecta exclusivamente a los actos jurídicos públicos ni, dentro de ellos, a los de promulgación de leyes u otras normas generales. Podemos perfectamente concebir ejemplos de disposiciones testamentarias que se enfrenten a la misma dificultad y que serían inaplicables. Es esa inaplicabilidad lo que anula al menos una de ellas. (Se deja como ejercicio al lector diseñar algunos de tales ejemplos en campos como el derecho de sucesiones, el derecho internacional de los tratados [en relación con el convenio de Viena], el derecho mercantil, el de familia etc. $)^{20}$

\section{Conclusión}

Nuestra indagación nos ha llevado a profesar y defender el principio de aplicación deóntica lo mismo que el de aplicación permisiva como principios de pura lógica, válidos en virtud de la naturaleza misma de la materia jurídica, e indispensables en el proceso de aplicación de la norma (pasar de una situación jurídica más general o abstracta a una más singular y concreta) y, a la postre, en el de cumplimiento de la misma (pues el cumplidor 
ha de afrontar como tarea imperativa, no la realización de una implicación, sino la de la apódosis, en el supuesto de la prótasis). Sin esos principios, una lógica deóntica carece de aplicabilidad y, por lo tanto, de interés práctico.

Hemos visto también que, si -en los casos no problemáticos- el uso del principio de aplicación deóntica es asunto de pura lógica, al alcance de cualquier sujeto inteligente y responsable de sus actos, en los casos difíciles se reserva a ciertas personas o instituciones, con ciertos requisitos procedimentales o solemnidades, para asegurar que el supuesto de hecho quede debidamente acreditado y convenientemente calificado para venir subsumido bajo la prótasis de la obligación implicativa. En tales casos corresponde al aplicador con potestad para hacerlo declarar o crear la situación jurídica que contiene la apódosis.

No parecen bien encaminadas las pesquisas que busquen otro fundamento que ése ni nada que viniera a ser una especie de aplicación al revés, salvo en el caso de la permisión (principio de limitación), cuyo papel, en el contexto aquí debatido, es muy modesto. Son infructuosas las demás tentativas, porque no hay nada que encontrar al respecto.

Por último, nuestro estudio revela que algunos actos jurídicos (promulgatorios o de otra índole) pueden resultar nulos por no reunirse ciertas condiciones fácticas para su validez, en el supuesto de que haya habido otros actos jurídicos válidos que han creado ya determinadas situaciones jurídicas. Ante esa colisión, o bien el nuevo acto es válido y destruye la situación jurídica hasta entonces existente, o bien es inválido y no consigue crear la nueva situación jurídica.

Lo fáctico y lo jurídico están, pues, imbricados uno con otro.

\section{Anejo: bosquejo del sistema LJ}

Propongo aquí un sistema reelaborado de lógica juridicial, LJ, muy afín a los que años atrás pusimos en pie, ${ }^{21}$ pero que incorpora algunas novedades (rectificando también algunos errores) ${ }^{22}$. Símbolo primitivo: ' $l$ ' (operador de licitud), con "vA" ( $v$ ' de 'vetatum', 'prohibido') que abrevia a " $l \mathrm{~A}$ " y "oA" que abrevia a "v A"; la lógica cuantificacional subyacente es el sistema de lógica transitiva (gradualista) P (una extensión no conservativa del cálculo del entailment $\mathrm{E}$ ). La negación ‘ $\neg$ ' es fuerte, y la ` ’ débil. La conectiva ' $\supset$ ' es un mero condicional: “A $\supset B$ " abrevia a " $\neg A \vee B " . ~ ' \wedge$ ' es la conyunción, ' $v$ ' es la disyunción, ' $\kappa$ ' denota impedimento (del griego 'kolúo’) y ' $\alpha$ 'un nexo de causalidad (del griego 'aitía'). ' $\rightarrow$ ' es la implicación (que indica que la prótasis es, a lo sumo, tan verdadera o existente como la apódosis; al paso que ' $\leftrightarrow$ ' es la implicación mutua. '\&' es una conyunción asimétrica: la fórmula "A\&B" abrevia a " $\neg \neg A$ B" (el valor veritativo de la fórmula conyuntiva sólo depende del segundo conyunto con tal que el primero no sea nulo).

- Principio de co-licitud $[\boldsymbol{l} \mathrm{A} \wedge l \mathrm{~B}] \rightarrow$ $l(\mathrm{~A} \wedge \mathrm{B})$

- Principio del efecto lícito: ([A $\alpha \mathrm{B}]$ $\& l \mathrm{~A}) \rightarrow \boldsymbol{l B}$

- Principio de no impedimento: $([\mathrm{A} \kappa \mathrm{B}] \& \boldsymbol{l} \mathrm{A}) \rightarrow \boldsymbol{v B}$

- Principios gemelos de aplicación: $o(\mathrm{~A} \rightarrow \mathrm{B}) \supset(\mathrm{A} \rightarrow \boldsymbol{o B})$ $l(\mathrm{~A} \rightarrow \mathrm{B}) \supset(\mathrm{A} \rightarrow l \mathrm{~B})$

Siempre que "A" y "B" designen estados de cosas contingentes de suyo y contingentes entre sí.

- Principios gemelos de bifurcación (con las mismas restricciones):

$[\boldsymbol{o}(\mathrm{A} \vee \mathrm{B}) \wedge \neg \mathrm{A}] \rightarrow \boldsymbol{o B}$

$[l(\mathrm{~A} \vee \mathrm{B}) \wedge \neg \mathrm{A}] \rightarrow l \mathrm{~B}$ 


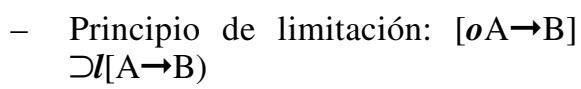

Aquí, además de exigir que " $\mathrm{A}$ " y "B" sean contingentes por separado y entre sí, requerimos también que "B" no contenga ninguna ocurrencia de un operador deóntico.

- Ley de exequibilidad (o de Bentham): $\boldsymbol{o}(\boldsymbol{o} \mathrm{A} \rightarrow \boldsymbol{l A})$

- Ley de autoimplicación lícita: $l(\mathrm{~A} \rightarrow \mathrm{A})$

- Reglas de inferencia:

- Regla de libertad: De que "vA" no sea un teorema se infiere " $l \mathrm{~A}$ "

- Regla de equivalencia: $\mathrm{Si}$ "A $\mathrm{A} \leftrightarrow \mathrm{B}$ ” es un teorema, también lo es " $l \mathrm{~A} \leftrightarrow l \mathrm{~B}$ ".

La extensión cuantificacional es sencilla: basta con entender el cuantificador universal como una conyunción (potencialmente) infinita y el existencial como una disyunción infinita. Así el principio de acumulación cuantificacional será: $\forall \mathrm{x} \boldsymbol{l} \mathrm{A} \rightarrow \boldsymbol{l} \forall \mathrm{xA}$ (lo que, si se me permite el latinajo, se diría: quidquid licet singillatim licet coniunctim).

\section{NOTAS}

${ }^{1}$ El trabajo de investigación que ha dado como resultado la redacción de este artículo forma parte del Proyecto:"Una fundamentación de los derechos humanos desde la lógica del razonamiento jurídico" [HUM2006-03669/FISO] del Ministerio de Educación y Ciencia, 2006-2009.

2 Especial en tanto en cuanto reflexiona sobre temas concretos de la acción humana, pero lo hace desde premisas filosóficas.

3 A lo largo del artículo voy a comentar diversas particularidades de este principio lógico, que podemos ver comouna regla de inferencia que nos habilita a extraer " $\mathrm{A} \rightarrow \boldsymbol{o B}$ " de la premisa " $\boldsymbol{o}(\mathrm{A} \rightarrow \mathrm{B})$ ".

${ }^{4}$ Entre otras cosas, queremos evitar tener que asumir que toda verdad necesaria, $\mathrm{V}$, es tal que $\boldsymbol{o V}$ sea una normavigente; al revés, es un corolario de nuestro tratamiento lógico que lo imposible es lícito, porque sólo sirve de algo prohibir hechos posibles, no hechos imposibles.

5 En el $\$ 8$ volveré sobre el problema de la subsunción.

${ }^{6}$ Esa disposición tiene lejanas raíces en la Lex Aquilia de 286 a.C. Tradicionalmente se ha concebido como reponsabilidad cuasi-delictual. En la bella prosa del CC napoleónico se estampó en el art. 1382: “Tout fait quelconque de l'homme qui cause à autrui un dommage oblige celui par la faute duquel il est arrivé à le réparer". Cae fuera de mi actual ámbito de consideración el tremendo debate sobre cómo la jurisprudencia contra legem, al norte y al sur de los Pirineos, ha ido convirtiendo la responsabilidad extracontractual en objetiva, lo cual en la práctica -dígase como se diga- significa responsabilidad también por caso fortuito. El movimiento jurisprudencial se inició en Francia en 1898 a propósito de la aplicación del art. 1384 CC francés acerca de la responsabilidad por hecho de cosas, mediante la técnica de la presunción: quien crea el peligro se presume (iuris tantum) haber actuado culposamente. ( $\mathrm{O}$ sea: se invertía la carga de la prueba.) Posteriormente se ha llegado a prescindir de esa técnica y de la doctrina del peligro para aplicar el art. 1902 español y su equivalente francés como estableciendo una obligación de reparar cualquier daño causado con o sin negligencia. V. Christian Lapoyade Deschamps, Droit des obligations, París: Ellipses, 1998, pp. 204ss. Sobre la evolución de la responsabilidad por daños en el derecho español, v. José Luis Lacruz Berdejo et al., Derecho de Obligaciones, Vol. 2, Madrid: Dykinson, 1999, pp. 448ss. Para cerrar esta nota, conviene decir que ese ensanchamiento de la responsabilidad extracontractual ha sido paralelo a una redefinición del caso fortuito, que la moderna doctrina ha querido interpretar como interrupción del nexo causal. V. Mario César Gianfelici, Caso fortuito y caso de fuerza mayor en el sistema de responsabilidad civil, Buenos Aires: Abeledo-Perrot, 1995, p.55.

7 V. Thinking and Doing, Dordrecht, Reidel, 1975.

8 Así reza el art. 954, 33 , de la Ley de Enjuiciamiento Civil de 1881, que -en esa materia- ha venido incorporada a la Ley 1/2000 actualmente vigente.

9 A pesar de las objeciones que en otro lugar formulé contra ese principio de desiteración: "Un enfoque no-clásico de varias antinomias deónticas", 
Theoria 7-8-9 (San Sebastián: 1988), pp. 67-94. Ese artículo pertenece a la etapa proto-gradualista, anterior a la creación de los sistemas de lógica juridicial (que podemos fechar en agosto de1995, con el Congreso internacional de lógica de Florencia). Sin embargo, mis objeciones a diversos axiomas deónticos con operadores iterados continuaron a lo largo de una serie de trabajos del equipo JuriLog de los años siguientes. Un escrúpulo que a menudo me llevó a ver con recelo axiomas con iteraciones deónticas (o sea: en los cuales un operador deóntico cayera bajo el alcance de otro) es que yo venía a identificar el que sea obligatorio (o lícito) que sea obligatorio (o lícito) que A con un deber (o un derecho) del legislador (o de aquel a quien corresponda) de emitir un acto jurídico que haga obligatorio (o lícito) A. Creo ahora que esa identificación era errónea. Sin duda, por el principio del efecto lícito y por el de no-impedimento (v. el Anejo de este artículo), las atribuciones del legislador están limitadas por los derechos constitucionalmente reconocidos, dado que la promulgación legislativa de una norma causa situaciones jurídicas de licitud o ilicitud. Mas eso no significa que el contenido semántico del aserto "ooA" sea "El legislador tiene que promulgar la obligación de A". No, "ooA"dice lo que dice: que es obligatorio que sea obligatorio que A". Seguramente es una novedad del sistema LJ propuesto en este trabajo (a diferencia de los anteriores) el admitir varios teoremas lógico-deónticos con iteraciones; p.ej.: "oA $\rightarrow \boldsymbol{l o A}$ ", "olA $\rightarrow l \mathrm{~A}$ ",

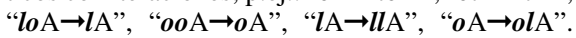
Persisten motivos de rechazo contra otras fórmulas, p.ej. "oA $\rightarrow \boldsymbol{o o} \mathrm{A}$ " y " $l \boldsymbol{l} \mathrm{A} \rightarrow \boldsymbol{l A}$ " (Nótese que estos dos últimos serían demostrables si añadiéramos el axioma " $o(\mathrm{~A} \rightarrow \mathrm{A})$ ”; ¡Dios nos libre!) Los méritos o deméritos de cada fórmula con iteraciones deónticas han de ser sopesados caso por caso. El hilo conductor es siempre el mismo: hay que reflexionar sobre cómo será un sistema de normas con, o sin, el principio sometido a examen, para averiguar si la introducción del principio es necesaria para otorgar validez a ciertos razonamientos jurídicos aparentemente válidos sin dejar colarse de rondón consecuencias jurídicas indeseables. Una discusión más pormenorizada del asunto excede los límites de este artículo.

10 V. su artículo "The Paradoxes of Deontic Logic: The Simplest Solution to All of Them in One Fell Swoop", en Hilpinen, R. (ed.) New Studies in Deontic Logic, Dordrecht: Reidel, 1981, pp. 37-85.

11 A nadie se le escapa que la posición defendida en este artículo desde la lógica juridicial reentronca con una tradición que - reaccionando contra la jurisprudencia de conceptos (precursora del normativismo)- recalcó los vínculos entre el derecho y los hechos sociales; tradición de los juristas sociólogos, principalmente de la escuela francesa a partir de Gény. V. Ramón Soriano, Sociología del derecho, Ariel, 1997, pp. 119ss.

12 En su libro Teoría pura del derecho (Bogotá: Temis, 1992, trad. J. Guerrero, p. 96), Mario G. Losano dice: "Tan radical es la separación kelseniana entre Sein y Sollen como dialéctica es la concepción de Georg Simmel sobre las relaciones entre realidad y deber-ser". Kelsen asume, en efecto, en su máxima radicalidad -que suavizará más tarde- la oposición total entre lo normativo y lo fáctico. Sobre las relaciones entre validez y eficacia, v. ibid.,pp. 142ss. V. también Juan Antonio García Amado, Hans Kelsen y la norma fundamental, Madrid: Marcial Pons,1996, pp. 124ss. V. también el estudio preliminar de Luis Recaséns Siches en Hans Kelsen, Compendio de teoría general del Estado, México: Colofón, 1992, pp. 17ss. (Trad. de L. Recaséns y J. de Azcárate.)

13 Una originalidad relativa. Como es bien sabido, dos de los máximos jusfilósofos decimonónicos, Savigny y Bentham, vincularon la vigencia normativa a circunstancias fácticas, estimando ambos que, de no concurrir determinados hechos, la norma no existe; a la vez, discreparon en lo tocante al influjo del derecho sobre la realidad social fáctica. V. Carlos Santiago Nino, Introducción al análisis del derecho, Ariel, 1991 (4ª ed.), pp. 299ss.

${ }^{14}$ La vinculación de lo jurídico y lo fáctico no ha sido ajena a todo el pensamiento jusfilosófico del siglo XX. Para Hart, la regla de reconocimiento es una cuestión de hecho. V. M ${ }^{\mathrm{a}}$ José Falcón y Tella, Concepto y fundamentode la validez del derecho, Madrid: Civitas, 1994, p.221. Sobre la noción de hecho normativo en Gurvitch (las normas son válidas porque responden a las exigencias que surgen del mismo fondo de la sociedad) y sobre la regla jurídica como ley de la sociedad en León Duguit, v. ibid, pp. 282ss. Duguit insiste en entender la ley como un imperativo hipotético, aunque le faltara el instrumental lógico para conceptualizar su idea de manera rigurosa.

15 Debo esta objeción a la lectura de Manuel Atienza, en su libro El Derecho como argumentación, Barcelona;Ariel, 2006, p. 140.

16 Este diálogo no pretende todavía brindar una respuesta concluyente a la objeción. Volveré sobre el asunto con mayor detenimiento en el $\S 13$.

17 Es profunda la afinidad jusfilosófica entre el enfoque que sustenta nuestra construcción de lógica juridicial y el de Joaquín Costa, para nosotros un precursor. Nuestra tesis principal -la defensa del principio de aplicación deóntica- sale por los fueros de la noción de hecho jurídico - esencial, desde luego, para la doctrina jurídica, pero poco atractiva 
para la mayoría de los filósofos del derecho del siglo XX. No es un azar que Joaquín Costa dedicara a esa noción una gran monografía, todavía hoy llena de interés: Teoría del hecho jurídico individual y social, Granada: Comares, 2000. (Ed. orginal 1880.)

18 Empecé a contestar a esa objeción más arriba, en el $§ 07$.

${ }^{19} \mathrm{El}$ adagio utile per inutile non uitiatur halla su plasmación en muchos artículos del CC, en los que las cláusulas inaplicables se tienen por no puestas (sin que anulen el contrato mismo). En él se inspira la Ley 7/1998 de condiciones generales de contratación, favoreciendo la nulidad parcial. Cf. art. 1258 CC. V. Lacruz, op.cit., II, p.561. También la jurisprudencia francesa ha evolucionado en lo tocante al régimen de la nulidad de los contratos, desde las draconianas disposiciones del art. 1172 del código napoleónico -según el cual cualquier condición inmoral o ilícita anula totalmente el convenio que depende de ella- a un principio de conservación del acto jurídico en lo que tenga de salvable. V. Jacques Flour et al., Droit civil: les obligations: L'acte juridique, DallozArmand Colin, 2002 (10 a ed.), p.373. Ese principio de conservación afecta a todas las esferas. En derecho internacional privado, se refleja en el Convenio de Roma de 1980-06-18 sobre la ley aplicable a los contratos internacionales, que desarrolla lineamientos jurídicos anteriores para instaurar unos cánones de dépeçage y de morcellement de los contratos; mecanismo ideado para otro fin, pero que -llegado el caso- permite minimizar y aislar las cláusulas invalidadas por motivo de nulidad. V. Yvon Loussouarn \& Pierre Bourel,
Droit international privé, París: Dalloz, 1996, $5^{\text {a }}$ ed., §378-3, pp. 422ss.

20 Aunque he mencionado sólo la nulidad de un acto como sanción por el intento de establecer una situción jurídica incompatible con la existente combinación jurídico-fáctica (salvo que el acto tenga poder para abrogar o revocar una norma o una situación jurídica, evitando así la incompatibilidad), hay frecuentemente otra solución: reinterpretar el contenido del acto jurídico de modo que no se produzca la colisión.

21 V. los siguientes arts. de Lorenzo Peña \& Txetxu Ausín: (1 ${ }^{\circ}$ " "Paraconsistent Deontic Logic with Enforceable Rights", Frontiers of Paraconsistent Logic, ed. por D. Batens, Ch. Mortensen, G. Priest \& J.-P. van Bendegem.Baldford (Inglaterra): Research Studies Press Ltd. (RSP) [Logic and Computation Series], 2000. ISBN 086302532, pp. 29-47. (2) "La deducción normativa", Doxa, vol 23, pp. 465-81. ( $\left.3^{\circ}\right)$ "Quantificational Entitlements and Relevantoid Deontic Logic", Logique et Analyse, $\mathrm{N}^{\mathrm{o}}$ 150-151-152 (1995), pp. 209-238. (4 $\left.{ }^{\circ}\right)$ "Arguing from Facts to Duties (and Conversely)", Proceedings of the 5th Conference of the International Society for the Study of Argumentation, ed. por Frans van Eemeren et alii. Amsterdam: Sic Sat, 2003. ISBN 90-74049-07-9, pp. 45-48.

22 P.ej. era erróneo, en nuestros sistemas anteriores, no haber sometido a las restricciones que aquí aparecen -ni a ninguna otra- los principios gemelos de bifurcación y de aplicación. En su versión irrectricta, acarreaban consecuencias cuasiparadójicas, que hacían prácticamente inservibles a nuestros sistemas de lógica juridicial. Felizmente había una solución, que es la que aquí figura. 